\title{
Through the looking glass: The first 20 years of thoracic aortic stent-grafting
}

\author{
D. Craig Miller, MD
}

It is difficult to believe that it has actually been 20 years since interventional radiologist Michael Dake and I implanted the first thoracic aortic stent-graft (now known as thoracic endovascular aortic repair [TEVAR]) at Stanford in July 1992 in a patient with an enlarging descending thoracic aortic false aneurysm 30 years after aortic coarctation repair. ${ }^{1}$ This was less than 2 years after Parodi and Palmaz's pioneering stent-graft repair of an abdominal aortic aneurysm in Buenos Aires. Tremendous progress has been accomplished since those early groundbreaking and frightening days of custom fabricating cumbersome, large, homebrewed stent-grafts with Palmaz stainless steel stents and navigating large, stiff $28 \mathrm{~F}$ sheath dilator delivery systems across tortuous, heavily diseased arteriosclerotic iliac arteries and up into diseased aortic arch segments with only rudimentary portable C-arm imaging. ${ }^{2,3}$ Major technical improvements have been accomplished during these 2 decades, and stent-grafts of the current generation are smaller and more conformable and can be deployed more safely and reproducibly. This has resulted in low perioperative morbidity and mortality, spawning an explosion in TEVAR use ${ }^{4-9}$; nevertheless, serious questions have subsequently arisen concerning poor long-term survival after TEVAR, inappropriate TEVAR overuse, and the hazy line that separates utility from futility. ${ }^{5,6,11-14}$ Looking back to reflect on where we have been can be constructive. We have a lot to celebrate as a result of the intrepid efforts of many in this field, and many lives have been saved, but let's see what we have learned during the last 2 decades of this technical wizardry and how we can improve results in the future.

After US Food and Drug Administration (FDA) approval of the first commercial TEVAR device (Gore TAG; W. L. Gore and Associates, Flagstaff, Ariz) in 2005, the balance between open surgical graft replacement and endovascular procedures swung to favor TEVAR, and the overall number of thoracic aortic repairs in the United States with either

From the Department of Cardiovascular and Thoracic Surgery, Stanford University School of Medicine, Stanford, Calif.

Disclosures: Dr Miller has nothing to disclose with regard to commercial support.

Read at The American Association for Thoracic Surgery Aortic Symposium, New York, New York, April 26-27, 2012.

Received for publication Sept 4, 2012; accepted for publication Nov 28, 2012.

Address for reprints: D. Craig Miller, MD, Department of Cardiovascular and Thoracic Surgery, Falk CVRB, Stanford University School of Medicine, Stanford, CA 94305-5247 (E-mail: dcm@stanford.edu).

J Thorac Cardiovasc Surg 2013;145:S142-8

0022-5223/\$36.00

Copyright (c) 2013 by The American Association for Thoracic Surgery

http://dx.doi.org/10.1016/j.jtcvs.2012.11.076 open or endovascular techniques also increased substantially. ${ }^{6,12,13}$ Other clinical challenges, such as acute complicated type $\mathrm{B}$ aortic dissection resulting from malperfusion or rupture and acute traumatic aortic tears, have been satisfactorily addressed by using various TEVAR devices off-label. Our group at Stanford treated our first patient with an acute complicated type B aortic dissection at Stanford in 1996, and we published the first series of such patients with acute dissection treated with TEVAR in $1999 .{ }^{3}$ Despite the absence of controlled prospective randomized trials or level I evidence, there is a growing body of observational evidence that emergency or urgent TEVAR for patients with acute type B dissection who are critically ill from major complications of rupture or malperfusion caused by true lumen collapse is lifesaving, and it constitutes the preferred therapeutic approach today. ${ }^{4}$ This is also the consensus regarding acute traumatic thoracic aortic injuries, albeit without any level I scientific evidence supporting this strategy. ${ }^{10,11}$

In light of the shift away from open surgical graft replacement to TEVAR during the last decade, even institutions that historically had large thoracic aortic surgical programs have regrettably lost their high level of expertise, which had yielded good outcomes in the past. The advantages of minimally invasive TEVAR in terms of lower early postoperative mortality and morbidity rates spawned broader use of endovascular approaches, including the aptly maligned "hybrid" arch and thoracoabdominal aortic procedures that resort to extra-anatomic revascularization of important end organs to create suitable anatomic landing zones for a stent-graft. The cumulative risk of these staged "debranching" hybrid strategies is often substantially higher than that of conventional open thoracic aortic surgical repair when the latter is performed in high-volume regional centers of surgical excellence. Hybrid TEVAR procedures were justified by claims that this treatment could now be offered to "inoperable" or very high-risk patients regardless of whether symptoms were present. Thus patients at higher and higher risk and with more severe medical comorbidities are now undergoing TEVAR. ${ }^{6,11-13}$

By 2004, we had compiled a total cumulative follow-up of 422 patient-years among our initial 103 patients treated at Stanford with a thoracic aortic stent-graft between 1992 and 1997; 48 patients remained at risk at 5 years and mean follow-up was $4.5 \pm 2.5$ years. ${ }^{5}$ Of these patients $60 \%$, or 62 individuals, had been judged unfit for open surgical graft replacement by an experienced cardiovascular surgeon. Independent risk factors portending a higher 

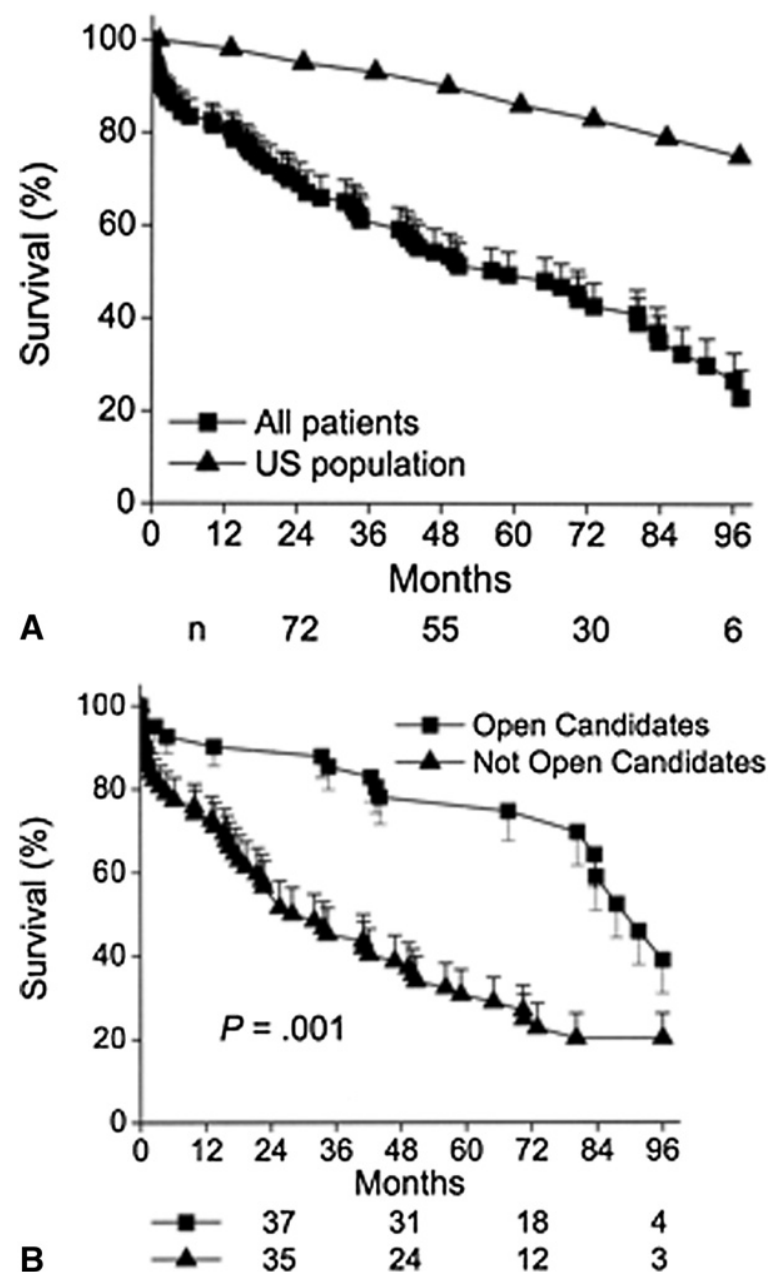

FIGURE 1. Five-year midterm survival for the initial 103 patients treated with TEVAR at Stanford between 1992 and 1997. (A) Actuarial survival estimates for all patients compared with an age- and gender-matched US population. (B) Survival estimates subdivided according to whether the patient was judged to be a reasonable open surgical candidate. Error bars $= \pm 1$ standard error. Reprinted with permission from: Demers P, Miller DC, Mitchell RS, Kee ST, Sze D, Razavi MK, et al. Midterm results of endovascular repair of descending thoracic aortic aneurysms with first-generation stent grafts. J Thorac Cardiovasc Surg. 2004;127:664-73.

likelihood of death were older age, previous stroke, and being judged not to be an open operable candidate. Overall survival was $49 \% \pm 5 \%$ at 5 years. Figure 1 illustrates the marked divergence in survival between the "operable" $(78 \% \pm 6 \%)$ and the "inoperable" $(31 \% \pm 6 \%)$ subgroups at 5 years. We concluded that more stringent patient selection was needed, because the potential benefits of TEVAR were overwhelmed by the medical problems in these "inoperable" patients, and we questioned whether patients without symptoms who were not open surgical candidates should even be offered TEVAR, because prevention of aneurysm rupture realistically would neither improve their quality of life nor extend their life expectancy. Sadly, these words were not widely read and accepted.
Walker and colleagues' 2010 survey $^{6}$ investigating changing US practice patterns and hospital outcomes for patients with unruptured descending thoracic aortic aneurysms between 2000 and 2007 used the National Inpatient Sample database, an administrative database that represents a stratified sample containing approximately $20 \%$ of all US hospital admissions, irrespective of age or payor. ${ }^{6}$ Focusing solely on hospitals that performed both open surgical and endovascular repair of descending thoracic aortic aneurysms, the annual rate of open surgical repair was 3.3 per million in 2000 through 2002, increased to 5.6 per million in 2003, and then declined to 3.1 per million in 2005; concurrently, TEVAR use quadrupled in 2 years from 1.2 per million in 2005 to 4.8 per million in 2007, such that the combined open and TEVAR annual rate totaled 7.9 per million population in 2007. TEVAR was used for older and sicker patients, as one would expect. In 2007, the estimated in-hospital mortality risk was similar between the open repair (1.35\% mortality) and TEVAR (1.91\% mortality) cohorts (relative risk, $0.71 ; 95 \%$ confidence interval [CI], $0.12-4.24 ; P=.7$ ), but complications occurred more commonly after open repair. TEVAR patients were more likely to be discharged to home. Importantly, Walker and colleagues ${ }^{6}$ noted that about two thirds of all TEVAR repairs in 2007 were carried out for "off-label" pathology (ie, for indications for which no controlled or rigorous comparative data existed to justify TEVAR). It was impossible to ascertain from the National Inpatient Sample database whether growing TEVAR use was due to more older, sicker "inoperable" patients now being treated or to patients with smaller aneurysms undergoing TEVAR. If the latter, Walker and colleagues ${ }^{6}$ emphasized that no clinical outcome data exist today that can justify lowering the aneurysm size threshold for treatment of patients with descending thoracic aortic aneurysms or otherwise altering the traditional surgical indications (as imperfect as they may be $\mathrm{b}^{7-9}$ ). They urged caution in expanding TEVAR use until future comparative effectiveness research focused on long-term clinical outcome, cost, radiation safety, and quality of life had clarified the implications of TEVAR treatment.

Scali and associates ${ }^{12}$ found that this increase in TEVAR use was even more dramatic for US Medicare beneficiaries (usually older than 65 years) in a Medicare MEDPAR administrative database study including both ruptured and unruptured descending thoracic and thoracoabdominal aneurysms and some aortic dissections: the annual rate of open or endovascular repairs increased by $60 \%$, from 10.8 per 100,000 to 17.8 per 100,000 between 1998 and 2007. ${ }^{12}$ Open surgical repair rates were stable (annual range, $10.7-12$ per 100,000), and the rate for TEVAR in 2007 was 5.8 per 100,000 (Figure 2, A). Interestingly, the rate of open surgical repair per capita varied widely across the United States, being highest in New England (double what it was in the Pacific and east south central regions), 

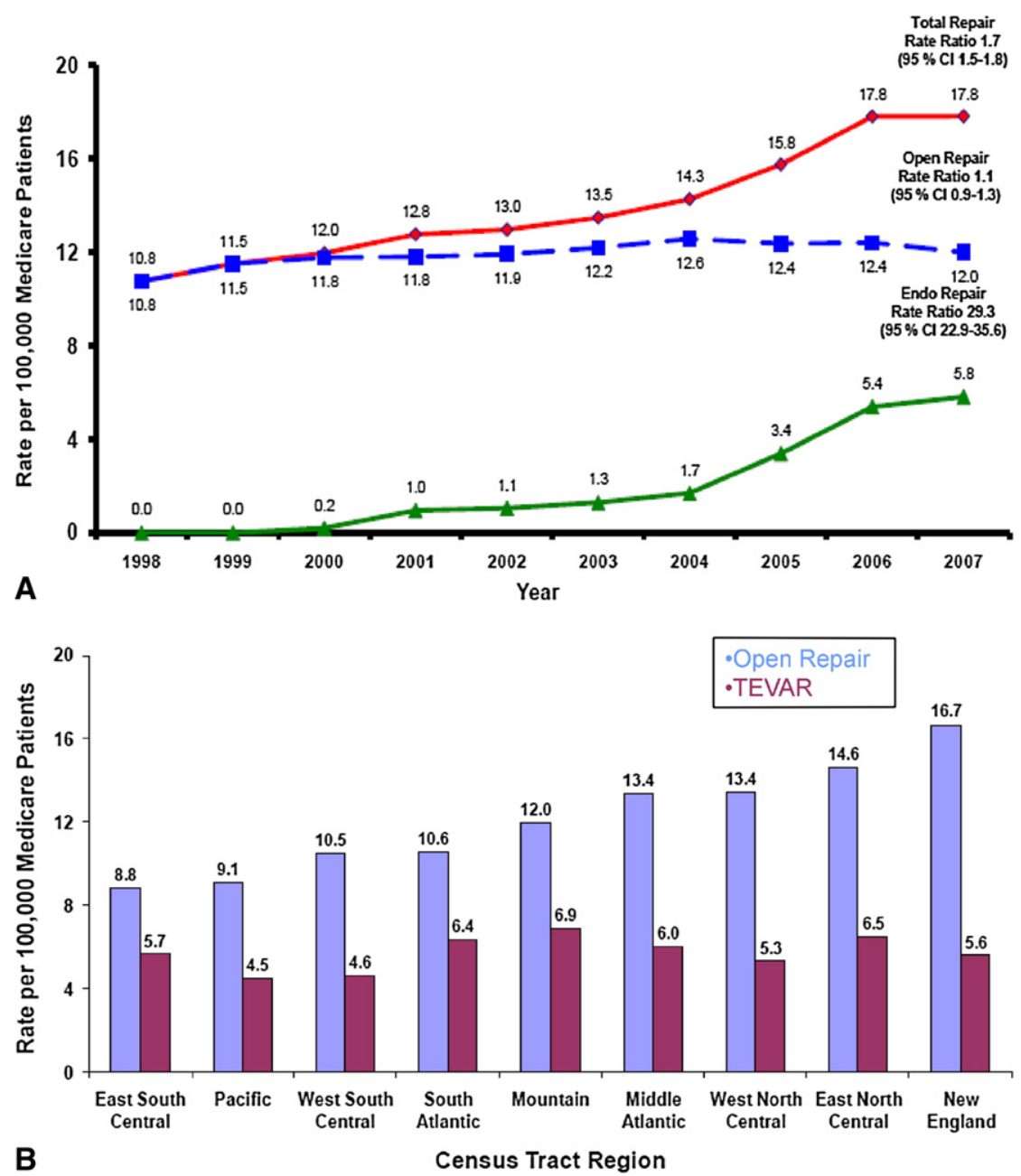

FIGURE 2. (A) Annual rate of total (diamonds), open surgical (squares), and endovascular (TEVAR, triangles) repair for descending and thoracoabdominal aneurysm in the US. Medicare patients between 1998 and 2007. (B) Regional variation in use of open and endovascular repair (TEVAR) of thoracic and thoracoabdominal aneurysms among Medicare beneficiaries in 2007. CI, Confidence interval. Reprinted with permission from: Scali ST, Goodney PP, Walsh DB, Travis LL, Nolan BW, Goodman DC, et al. National trends and regional variation of open and endovascular repair of thoracic and thoracoabdominal aneurysms in contemporary practice. $J$ Vasc Surg. 2011;53:1499-505.

in the upper Midwest, and in the middle Atlantic regions in 2007, whereas the TEVAR rate was uniform across the country (Figure 2,B).

Cheng and colleagues, ${ }^{10}$ on behalf of the European Association of Cardiothoracic Surgery, embarked on a massive meta-analysis that inspected 38 nonrandomized comparative and 4 registry publications with metaregression to account for unbalanced baseline risk factors. Many series were composed of young patients with traumatic aortic tears. End points were early stroke and spinal cord injury and 30-day, 1-year, and 2- to 3-year survivals. Compared with open surgical repair, TEVAR was associated with lower risk of all-cause mortality at 30 days (odds ratio, $0.44 ; 95 \% \mathrm{CI}, 0.33-0.59$ ) and of paraplegia (odds ratio, $0.42 ; 95 \% \mathrm{CI}, 0.28-0.63$ ); however, this survival advantage had disappeared by 1 and 2 to 3 years (Figure 3 ). Because no sustained survival benefit of TEVAR relative to open graft replacement was seen, Cheng and colleagues ${ }^{10}$ argued that restriction of TEVAR use to on-label indications and more stringent patient selection are sensible until more long-term information becomes available.

Looking at the midterm results of "real-world" TEVAR use is more sobering. As reported by Lee and colleagues ${ }^{11}$ from the University of Florida in 2011, 4-year overall survival after TEVAR was only $53 \% \pm 4 \%$ (median followup of 299 days among 400 patients). ${ }^{11}$ Twenty-five percent of patients had acute or chronic aortic dissection, $6 \%$ had a traumatic aortic transection, and $49 \%$ had aneurysms. A sophisticated multivariable risk model segregated the patients into 3 terciles: the 1-year survival estimate was only $20 \%$ in the high risk tercile, 2-year survival was approximately $60 \%$ for the intermediate risk group, and 3 -year survival was about $60 \%$ in the low-risk tercile (Figure 4 ). These poor survival rates were disappointing; Lee and 


\begin{tabular}{lrrrr} 
Study name & \multicolumn{4}{c}{ Statistics for each study } \\
& $\begin{array}{r}\text { Odds } \\
\text { ratio }\end{array}$ & $\begin{array}{c}\text { Lower } \\
\text { limit }\end{array}$ & $\begin{array}{c}\text { Upper } \\
\text { limit }\end{array}$ & p-Value \\
Fairman 08 (VALOR)0.741 & 0.440 & 1.247 & 0.259 \\
Matsumura 08 & 0.531 & 0.221 & 1.276 & 0.157 \\
Multicenter & 0.679 & 0.434 & 1.063 & 0.090 \\
Amabile 04 & 0.368 & 0.013 & 10.178 & 0.555 \\
Broux 06 & 0.591 & 0.090 & 3.864 & 0.583 \\
Buz 2008 & 0.958 & 0.365 & 2.514 & 0.931 \\
Dick 2008 & 2.143 & 0.756 & 6.074 & 0.152 \\
Doss 05 & 0.148 & 0.016 & 1.358 & 0.091 \\
Kasirajan 03 & 0.250 & 0.020 & 3.100 & 0.280 \\
Kokotsakis 07 & 0.900 & 0.072 & 11.254 & 0.935 \\
Najibi 02 & 0.438 & 0.070 & 2.728 & 0.376 \\
Nienaber 99 & 0.076 & 0.004 & 1.594 & 0.097 \\
Patel 08 & 0.918 & 0.404 & 2.090 & 0.839 \\
Single center & 0.806 & 0.492 & 1.323 & 0.394 \\
Overall & 0.734 & 0.526 & 1.023 & 0.068
\end{tabular}

A $1^{2}=0 \%$

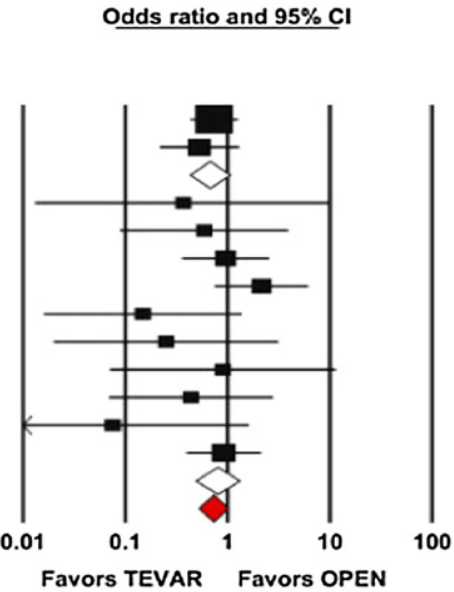

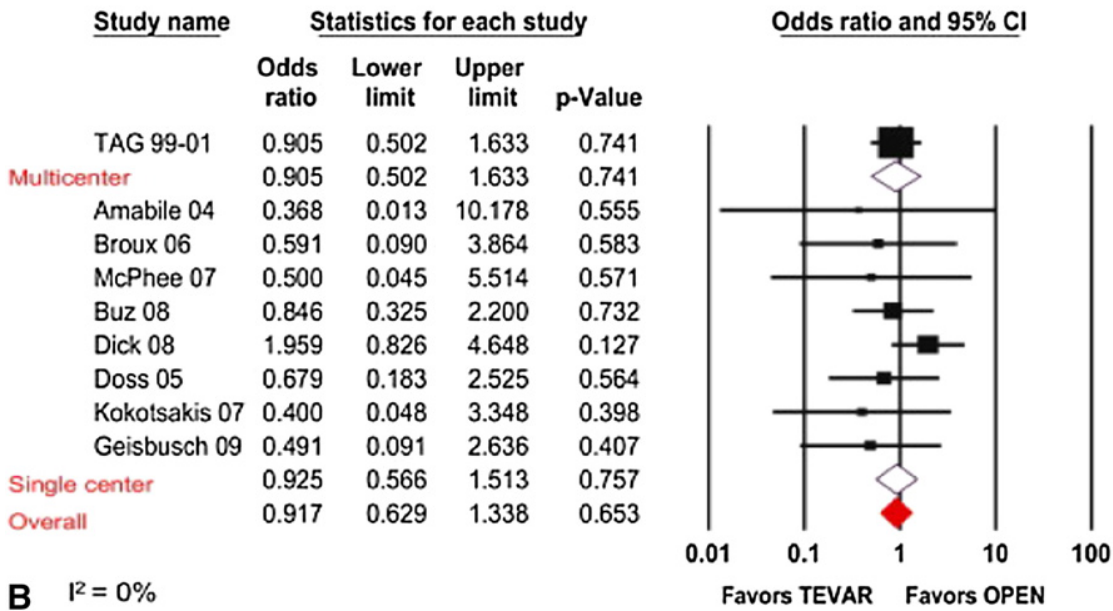

FIGURE 3. Meta-analyses of mortalities for thoracic endovascular aortic repair (TEVAR) versus open surgery. The odds ratio for death from each included study is plotted. A pooled estimate of overall odds ratio (diamonds) and $95 \%$ confidence intervals (CI, width of diamonds) summarizes the effect size with the random effects model. Effects to the left of 1.0 favor thoracic endovascular aortic repair; effects to the right favor open surgery. When the horizontal bars of an individual study, or the pooled diamond width, cross 1.0, the effect is not significantly different. The $\mathrm{I}^{2}$ for heterogeneity was not significant, suggesting homogeneity in effect size across each study. Reprinted with permission from: Cheng D, Martin J, Shennib H, Dunning J, Muneretto C, Schueler S, et al. Endovascular aortic repair versus open surgical repair for descending thoracic aortic disease a systematic review and meta-analysis of comparative studies. J Am Coll Cardiol. 2010;55:986-1001. A, Meta-analysis comparing death at 1 year for thoracic endovascular aortic repair versus open surgery. B, Metaanalysis comparing death at 2 to 3 years for thoracic endovascular aortic repair versus open surgery.

colleagues ${ }^{11}$ concluded that a combination of faulty patient selection and TEVAR treatment failure was to blame and emphasized that improved patient selection was mandatory to avoid futile TEVAR procedures in very old, frail, and sick patients with limited life expectancy.

Goodney and colleagues ${ }^{13}$ from Dartmouth again exhaustively analyzed Medicare administrative database claims data on 15,305 patients in the United States who underwent open or TEVAR repair of an intact or ruptured thoracic aortic aneurysm between 1998 and 2007. Attempts were made to exclude "hybrid procedures." Overall, TEVAR carried a lower early mortality risk. Unexpectedly, however, survivals at 1 and 5 years for those with unruptured aneurysms were higher for patients treated with open surgical repair than for those treated with TEVAR (Figure 5, A). This surprising survival advantage after open repair was also present when the cohorts were risk adjusted (nonblack men, younger than 75 years, Charlson score $<2$, operation after 2003; Figure $5, B$ ). In the propensity-matched analysis of 550 patient pairs ( $65-75$ years old) selected from the lowest risk quartile and operated on in the last 2 years of the study period (2005-2007), perioperative mortalities were similar $(4.5 \% ; 95 \%$ CI, $2.8 \%-6.2 \%$ for the TEVAR group vs $4.2 \% ; 95 \%$ CI, $2.5 \%-5.8 \%$ for the open group; $P=.78$ ); again, however, 5 -year survival was significantly worse for those undergoing TEVAR $(73 \%$; 95\% CI, 68\%-76\%]) than for those undergoing open surgical repair $(81 \% ; 95 \%$ CI, $77 \%-85 \% ; P=.007$; Figure $5, C$ ). When outcomes were analyzed according to era (before vs after TEVAR's FDA approval), the TEVAR patients after 2005 were a little 


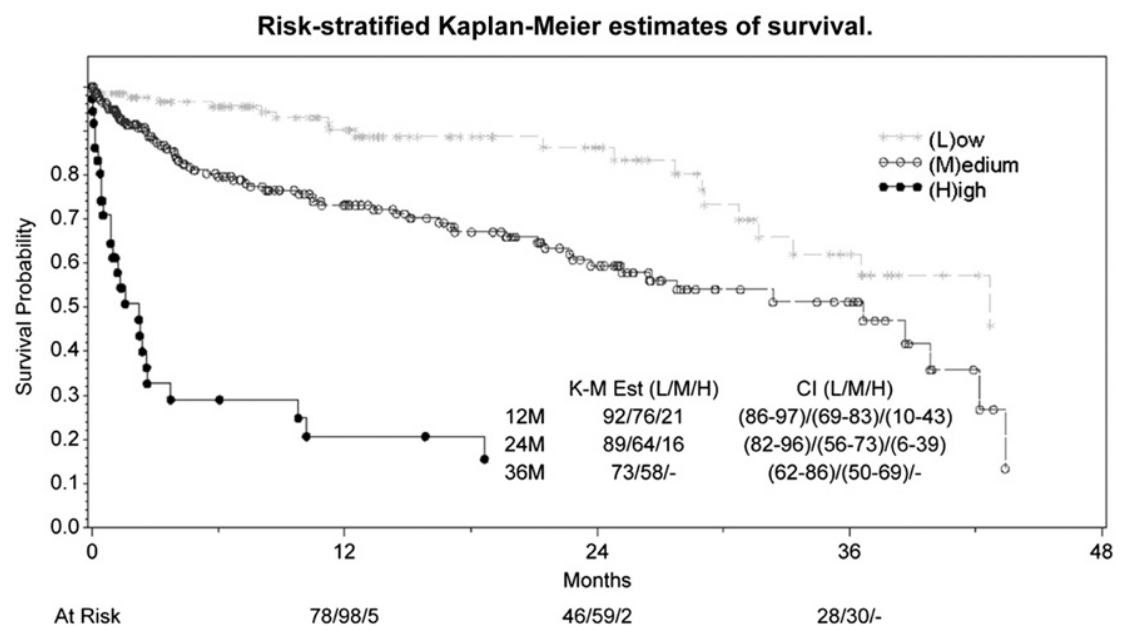

FIGURE 4. Risk-stratified Kaplan-Meier estimates ( $K$ - $M$ Est) of survival. $C I$, Confidence interval; $L / M / H$, low/middle/high. Reprinted with permission from: Lee WA, Daniels MJ, Beaver TM, Klodell CT, Raghinaru DE, Hess PJ Jr. Late outcomes of a single-center experience of 400 consecutive thoracic endovascular aortic repairs. Circulation. 2011;123:2938-45.

older but otherwise had clinical characteristics similar to those of the earlier TEVAR patients. There were no significant differences in TEVAR perioperative and 3-year mortalities when comparing TEVAR before 2005 with TEVAR after $2005 .{ }^{13}$ In contrast, the open surgical repair patients after commercial stent-graft FDA approval in 2005 were less sick than those operated on before 2005, which corresponded pari passu with a drop in open graft replacement perioperative mortality from $8.4 \%$ to $5.4 \%$ and with a better 3 -year survival. This "real world" US experience demonstrated that some higher risk patients being offered TEVAR did not benefit in terms of survival. It was not possible in this administrative database study to determine whether the TEVAR patients were dying from aortic complications, TEVAR treatment failure, or other comorbidities. Goodney and colleagues ${ }^{13}$ concluded that low-risk patients should undergo open surgical graft replacement at regional centers with high thoracic aortic surgical volumes and superior clinical track records. They also warned that before the use of TEVAR expands further it is necessary to perform further analyses to define a truly high-risk patient cohort for which TEVAR is not beneficial or is even futile. The proposed FDA prospective "Post-Approval Studies", which will apply to the manufacturers when new stent-graft devices or new indications for TEVAR are approved, are rigorous and will address this dilemma by providing stronger and much more robust clinical information than any registry can make available.

A recent report from Duke including 297 patients by Shah and colleagues ${ }^{14}$ showed similar somber results. As more and more patients were treated with TEVAR, the 5-year survival fell. Most known causes of death were related to cardiovascular and pulmonary problems. Regardless of quality of life and cost-effectiveness considerations, these observational data again make it clear that TEVAR therapy is being applied in a futile manner in many cases. The perverse economic incentives in the United States to perform procedures regardless of effectiveness and irrespective of cost certainly has not helped. This situation should drive physicians, who so far have been unwilling or unable to identify asymptomatic patient subsets in which TEVAR should not be offered because the underlying comorbidities pose a greater risk of death than does the aortic disease, to conduct multi-institutional studies to elucidate these factors.

It is our obligation as caring and compassionate physicians with overarching societal responsibilities not to shy away from these difficult and uncomfortable treatment decisions. Expensive technology for technology's sake is unaffordable and unsustainable, and it will doom future innovation if we do not learn how best to apply the wizardry of our new marvelous TEVAR tool kits and devices. We must always put the individual patient's welfare first, suppressing our egos and personal financial considerations. This approach is ideal for a surgeon who can offer either TEVAR or a safe open surgical aortic reconstruction and can appreciate clearly when the patient's other illnesses overwhelm the odds of any treatment returning the patient to a meaningful quality of life. Physicians from all disciplines must have the courage to recommend only medical therapy when any other treatment would be futile. Alternatively, another reasonable approach when combined open and endovascular expertise does not reside within a single surgical specialty is to evaluate patients with descending thoracic aortic pathology together with other involved physicians as a group (a thoracic aortic team) to decide whether treatment is justified and warranted; this initial step is far and away the most important decision and must rely on the surgeon's expertise and judgment. If treatment is 


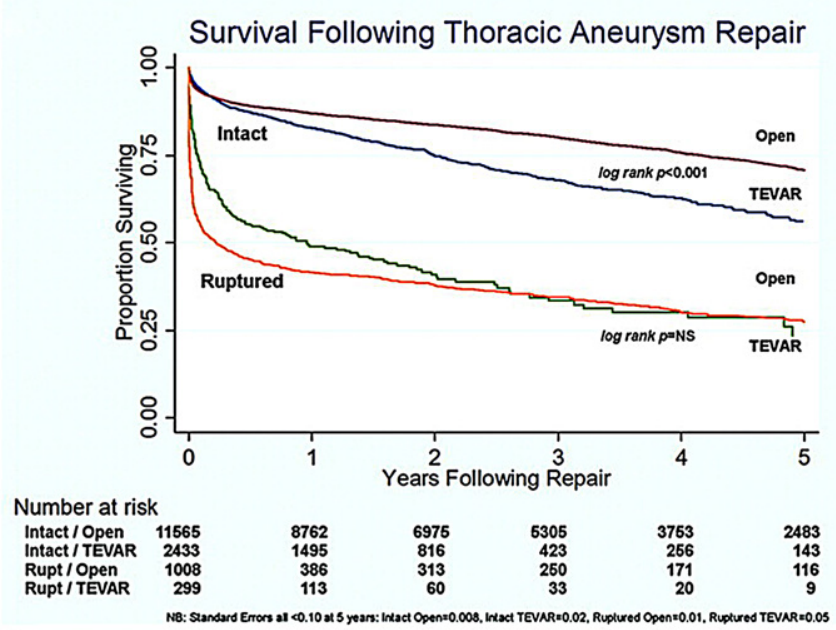

A

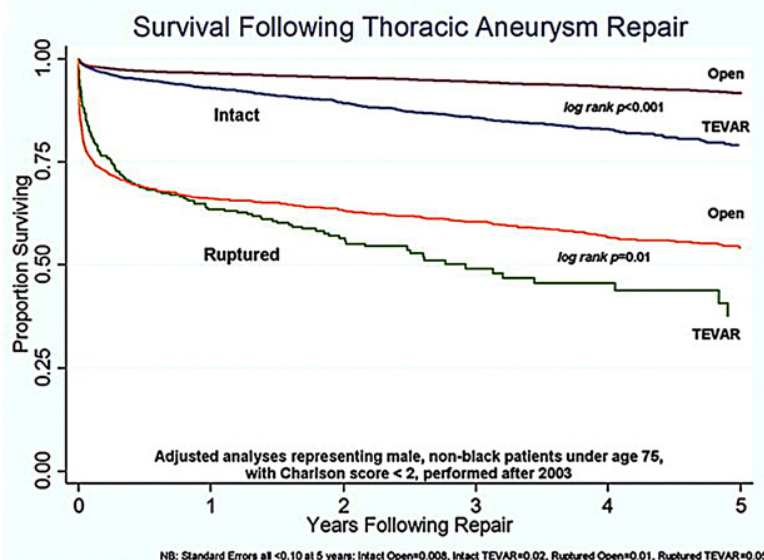

B

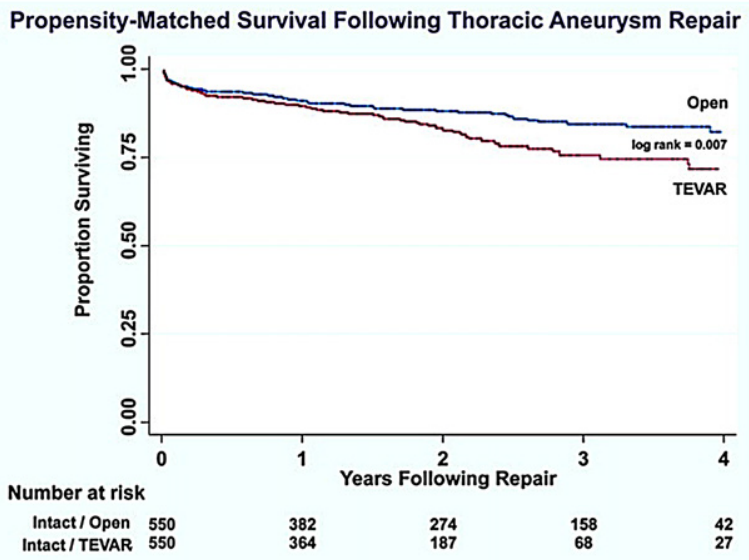

FIGURE 5. Unadjusted 5-year survivals for patients with thoracic aneurysms by procedure type and diagnosis. TEVAR, Thoracic endovascular aortic repair. Reprinted with permission from: Goodney PP, Travis L, Lucas FL, Fillinger MF, Goodman DC, Cronenwett JL, et al. Survival after open versus endovascular thoracic aortic aneurysm repair in an observational study of the Medicare population. Circulation. 2011;124:2661-9. A, Survival after thoracic aneurysm repairs. B, Survival after thoracic aneurysm repairs performed after 2002; adjusted analyses representing male, nonblack patients younger than 76 years with Charlson score less than 2. C, Propensity-matched survivals after thoracic aneurysm repair.

indicated and prudent, then the thoracic aortic team can decide whether open surgical repair or TEVAR is most appropriate for each individual patient. Finally, the actual procedure can be performed together or independently, depending on the environment of the institution.

Lamentably, the rhetorical questions our group posed in 2004 about TEVAR and appropriate patient selection remain unanswered today ${ }^{5}$ :

[W]e cannot definitively answer the philosophical question each individual physician must address and the ethical question society must face concerning whether stent-grafting should be withheld in elderly patients with asymptomatic aneurysms who are not open operative candidates. ... The soberingly dismal life expectancy in patients not judged suitable for open surgical repair... is a direct reflection of patient selection criteria. What we do know is that stentgrafting in asymptomatic patients does not improve quality of life; indeed, a cynic would term this "futile therapy" and submit that preventing aneurysm rupture by stent grafting only prolongs patient suffering due to their multiple other debilitating medical diseases. Just because we can treat does not necessarily mean we should treat. ...

This dilemma is analogous to what we are facing in the new field of transcatheter percutaneous aortic valve replacement (TAVR), where the line between utility and futility (PARTNER trial cohort $\mathrm{C}$ patients) has yet to be defined clearly. The 2012 Medicare TAVR National Coverage Decision calls for all TAVR patients to be entered into a national database so that outcomes and patient selection criteria can be analyzed and refined. Because hospital and physician 
reimbursement by Medicare is at stake, this will put the responsibility squarely on the physicians' shoulders to select patients extraordinarily carefully for TAVR. This should apply equally well to TEVAR.

In summary, the revolutionary first 20 years of TEVAR have been punctuated by many sterling successes and some failures, but today TEVAR enables many "inoperable" and high-risk patients with descending thoracic aortic aneurysms, penetrating ulcers, and localized false aneurysms to be treated relatively noninvasively. TEVAR can be a lifesaving emergency treatment for patients with complicated acute type B aortic dissections, and it plays a major (albeit unproven) role in the urgent treatment of patients with acute traumatic aortic transections. Patients with other aortic pathologies, such as chronic aortic dissection, are being treated with TEVAR; whether this is effective, however, will remain unknown until the proper studies (ideally randomized, controlled trials) are conducted and analyzed.

It is a pity that only 2 randomized, controlled trials have been carried out in the entire field of TEVAR. Nienaber and associates' Investigation of STEnt Grafts in Aortic Dissection (INSTEAD) trial ${ }^{15}$ compared medical therapy with TEVAR in patients with chronic, uncomplicated type B aortic dissections who were enrolled between 2 and 52 weeks after the onset of the dissection. The INSTEAD results were negative at 2 years in terms of clinical end points; however, favorable aortic remodeling was observed in the TEVAR subgroup (false lumen thrombosis in $91 \%$ vs only in $19 \%$ of the medically treated patients). Ongoing INSTEAD follow-up to 5 years is in progress, however, and preliminary indications suggest that TEVAR may confer a late survival advantage. The ADSORB (A Prospective Randomized Trial in Acute Uncomplicated Type B Dissections) trial ${ }^{16}$ comparing TEVAR versus medical therapy in patients with uncomplicated acute type $\mathrm{B}$ dissection is incomplete, and enrollment has been slow; the trial design was recently changed dropping the numbers of subjects from 250 to 60 .

This field desperately needs more randomized trials to be done, with the most valuable clinical questions being TEVAR versus open surgical repair of chronic aortic dissections of the descending thoracic aorta and TEVAR versus medical management of "anatomically high-risk" patients with acute type B dissections. The high use of TEVAR has been seriously questioned with respect to appropriateness, abuse, and, more compellingly, futility, as evidenced by the poor 5-year survivals. ${ }^{11,13,14}$ Future comparative effectiveness (survival, complications, quality of life, radiation safety) and cost-effectiveness research examining 5- to 10-year outcomes is necessary to refine patient selection criteria so that we can make smarter decisions regarding which patient should be treated and whether with open surgical graft replacement or with TEVAR.

Finally, physicians from all disciplines must summon the courage to not treat patients with asymptomatic aneurysms when advanced comorbid medical conditions and age would overwhelm any potential benefit TEVAR might provide in terms of reducing aneurysm rupture risk or restoring a semblance of reasonable quality of life. That is, we all just need to learn to apply TEVAR in a more intelligent fashion.

\section{References}

1. Dake MD, Miller DC, Semba CP, Mitchell RS, Walker PJ, Liddell RP. Transluminal placement of endovascular stent/grafts for the treatment of descending thoracic aortic aneurysms. N Engl J Med. 1994;331:1729-34.

2. Dake MD, Miller DC, Mitchell RS, Semba CP, Moore KA, Sakai T. The "first generation" of endovascular stent-grafts for patients with descending thoracic aortic aneurysms. J Thorac Cardiovasc Surg. 1998;116:689-703; discussion 703-4.

3. Dake MD, Kato N, Mitchell RS, Semba CP, Razavi MK, Shimono T, et al. Endovascular stent-graft placement for the treatment of acute aortic dissection. N Engl J Med. 1999;340:1546-52.

4. White RA, Miller DC, Criado FJ, Dake MD, Diethrich EB, Greenberg RK, et al. Report on the results of thoracic endovascular aortic repair for acute, complicated, type B aortic dissection at 30 days and 1 year from a multidisciplinary subcommittee of the Society for Vascular Surgery Outcomes Committee. J Vasc Surg. 2011;53:1082-90.

5. Demers P, Miller DC, Mitchell RS, Kee ST, Sze D, Razavi MK, et al. Midterm results of endovascular repair of descending thoracic aortic aneurysms with first-generation stent grafts. J Thorac Cardiovasc Surg. 2004;127:664-73.

6. Walker KL, Shuster JJ, Martin TD, Hess PJ Jr, Klodell CT, Feezor RJ, et al. Practice patterns for thoracic aneurysms in the stent graft era: health care system implications. Ann Thorac Surg. 2010;90:1833-9.

7. Svensson LG, Kouchoukos NT, Miller DC, Bavaria JE, Coselli JS, Curi MA, et al. Expert consensus document on the treatment of descending thoracic aortic disease using endovascular stent-grafts. Ann Thorac Surg. 2008;85(1 Suppl): S1-41.

8. Coady MA, Ikonomidis JS, Cheung AT, Matsumoto AH, Dake MD, Chaikof EL, Cambria RP, et al. Surgical management of descending thoracic aortic disease: open and endovascular approaches: a scientific statement from the American Heart Association. Circulation. 2010;121:2780-804.

9. Hiratzka LF, Bakris GL, Beckman JA, Bersin RM, Carr VF, Casey DE Jr, et al. 2010 ACCF/AHA/AATS/ACR/ASA/SCA/SCAI/SIR/STS/SVM guidelines for the diagnosis and management of patients with Thoracic Aortic Disease: a report of the American College of Cardiology Foundation/American Heart Association Task Force on Practice Guidelines, American Association for Thoracic Surgery, American College of Radiology, American Stroke Association, Society of Cardiovascular Anesthesiologists, Society for Cardiovascular Angiography and Interventions, Society of Interventional Radiology, Society of Thoracic Surgeons, and Society for Vascular Medicine. Circulation. 2010; 121:e266-369.

10. Cheng D, Martin J, Shennib H, Dunning J, Muneretto C, Schueler S, et al. Endovascular aortic repair versus open surgical repair for descending thoracic aortic disease: a systematic review and meta-analysis of comparative studies. J Am Coll Cardiol. 2010;55:986-1001.

11. Lee WA, Daniels MJ, Beaver TM, Klodell CT, Raghinaru DE, Hess PJ Jr. Late outcomes of a single-center experience of 400 consecutive thoracic endovascular aortic repairs. Circulation. 2011;123:2938-45.

12. Scali ST, Goodney PP, Walsh DB, Travis LL, Nolan BW, Goodman DC, et al. National trends and regional variation of open and endovascular repair of thoracic and thoracoabdominal aneurysms in contemporary practice. J Vasc Surg. 2011; 53:1499-505.

13. Goodney PP, Travis L, Lucas FL, Fillinger MF, Goodman DC, Cronenwett JL, et al. Survival after open versus endovascular thoracic aortic aneurysm repair in an observational study of the Medicare population. Circulation. 2011;124: 2661-9.

14. Shah AA, Barfield ME, Andersen ND, Williams JB, Shah JA, Hanna JM, et al. Results of thoracic endovascular aortic repair 6 years after United States Food and Drug Administration approval. Ann Thorac Surg. 2012;94:1394-9.

15. Nienaber CA, Rousseau H, Eggebrecht H, Kische S, Fattori R, Rehders TC, et al. Randomized comparison of strategies for type B aortic dissection: the Investigation of STEnt Grafts in Aortic Dissection (INSTEAD) trial. Circulation. 2009; 120:2519-28

16. Brunkwall J, Lammer J, Verhoeven E, Taylor P. ADSORB: a study on the efficacy of endovascular grafting in uncomplicated acute dissection of the descending aorta. Eur J Vasc Endovasc Surg. 2012;44:31-6. 